\title{
Asthma Programme in Finland: the quality of primary care spirometry is good
}

\section{*Leena E Tuomisto ${ }^{\text {, }}$ Vesa Jarvinen ${ }^{\mathrm{b}}$, Jukka Laitinenc, Marina Erhola ${ }^{\mathrm{d}}$, Minna Kaila ${ }^{\mathrm{e}}$ Pirkko E Brander ${ }^{f}$}

a Pulmonary Department, Seinajoki Central Hospital, Seinajoki, Finland

${ }^{b}$ Department of Clinical Physiology, Hospital District of Helsinki and Uusimaa, Hyvinkaa Hospital, Hyvinkaa, Finland

c Pulmonary Department, Koskiklinikka, Tampere, Finland

d Department of General Practice, The Municipal Joint Union for Public Health, Hameenlinna, Finland

e Department of Pediatrics, Tampere University Hospital and Finohta / Stakes Tampere Satellite Office, Finland

${ }^{\dagger}$ Department of Pulmonary Medicine, Hospital District of Helsinki and Uusimaa, Hyvinkaa Hospital, Hyvinkaa, Finland

Received 8th January 2008; resubmitted 4th March 2008; revised 19th June 2008; accepted 20th June 2008; online 2nd October 2008

\begin{abstract}
Aims: To assess the quality of primary care spirometry by visual inspection of the flow-volume expiratory curve and to study the quantity of clinical information provided on the spirometry report sheets.

Methods: Retrospective audit of 868 expiratory flow-volume curves referred to three pulmonary clinics assessed against five predefined quality criteria. Clinical information included on the spirometry report sheets, was alsö Collected.

Results: Quality was good in $78 \%$ of pre-bronchodilation curves and in $80 \%$ of post-bronchodilation curves. Obtaining a sharp PEF value and full vital capacity exhalation seemed to be the critical points of heasurement. Inter-rater reliability of the curve assessment was mainly good. Data on where the spirometry took place, and comments on the use of respiratory medication and patient co-operation were often lacking.

Conclusions: The quality of primary care spirometyewas good. Adequate clinical information on the report sheets would further improve the quality of this diagnostic process.

(c) 2008 General Practice Airways Groun. All rights reserved.

L Tuomisto, et al. Prim Care Resp 12008; 17(4): 226-231.

doi:10.3132/pcrj.2008.00053
\end{abstract}

Keywords asthma, primary care, spirometry, quality, flow-volume curve, assessment

\section{See linked Discussion paper by Enright on page 238}

\section{Introduction}

Spirometry is the most frequently used basic diagnostic test in pulmonary medicine. Guidelines and programmes concerning obstructive airway diseases have led to the increasing availability and use of spirometry in primary care settings. ${ }^{1,2}$ Spirometry seems to influence the general practitioner's (GP's) decision-making process not only by reducing diagnostic uncertainty, but also by increasing the use of additional diagnostic tests and referral to specialist care. ${ }^{3}$ Diagnosis of asthma is often dependent on repetitive lung function tests before and after initiation of anti-asthma treatment often started by a GP. When a patient with suspected asthma or poor asthma control is referred to specialist care, copies of previous high quality spirometry measurements with adequate clinical information enhance the management process.

The quality and interpretation of primary care spirometry measurements have been a concern in previous studies. ${ }^{4-6}$ Training has been shown to (at least temporarily) enhance the test quality. ${ }^{4}$ Spirometry interpretation should begin with an overview of the technical quality of the manoeuvre and the clinical information given on the report. Omitting the quality review and relying only on numerical results for clinical

\footnotetext{
* Corresponding author: Dr Leena Tuomisto, Pulmonary Department, Seinajoki Central Hospital, Huhtalantie 53, Seinajoki, 60220, Finland Tel: +358408457163 Fax: +35864154989 E-mail: leena.tuomisto@gmail.com
} 
decision-making is a common mistake, which is more easily made by those who are dependent upon computer interpretations.? Good quality spirometry is the result of both acceptable performance of the maximal exhalation manoeuvre and regular calibration of the equipment. The key check points of the maximal exhalation manoeuvre are the start, upslope, peak, and end of the curve; in addition, clinical information on circumstances such as the co-operation of the patient, current respiratory medication, and smoking status are important.

The main objective of the Finnish asthma programme (1994-2004) was to increase knowledge and recognition of asthma in primary care. ${ }^{8}$ One of the measures used to achieve this was to train nurses to perform, and GPs to use and interpret, flow-volume spirometry curves. ${ }^{9}$ National guidelines for laboratories and primary care units on how to measure and assess spirometry curves were first published in 1995. ${ }^{10}$ Thus, in 2001, spirometry was available in $95 \%$ of Finnish health care centres, ${ }^{11}$ and was actively used. In a previous study of asthma-related referral letters, we showed that preand post-bronchodilation spirometry measurements were included with the specialist referral letter more often in 2001 than in 1994 (32\% vs 5.3\%);12 furthermore, GPs prescribed asthma medication more actively, and preventive asthma medication was mentioned in 26\% of letters in 2001.

Spirometry report sheets may provide important diagnostic clues to the specialist only if the quality of the spirometry curves is acceptable, and adequate information on the spirometry session and patient history Gre included. The aim of this study was to assess the quality of primary care spirometry from the consulting specialist's viewpoint by visual analysis of the expiratory flow-volume curves and by evaluating the quantity of clinical information on the report sheets provided with the referral letters.

\section{Methods}

This study is part of the systematic evaluation of the Finnish asthma programme..$^{11-14}$ The methodology is a retrospective medical record audit.

Quality criteria for the flow-volume curve based on American Thoracic Society quality criteria ${ }^{15}$ were developed by the study group, which comprised six specialists representing four different specialities: clinical physiology (JL and $\mathrm{VJ}$ ), pulmonology (PB and $\mathrm{LT}$ ), primary care (ME) and allergology (MK). These criteria were used for visual assessment of the expiratory curves. The flow-volume curves were graded "good" if all five criteria were present (Figure 1).

Piloting of the feasibility of the quality criteria was performed. Two clinical physiologists ( $\mathrm{JL}$ and $\mathrm{VJ}$ ) and two pulmonary physicians (PB and LT) reviewed all five criteria of 36 spirometry curves; 14 of these included both the pre- and
Figure 1. Quality criteria of the expiratory flow-volume loop (based on ATS quality criteria, 15).

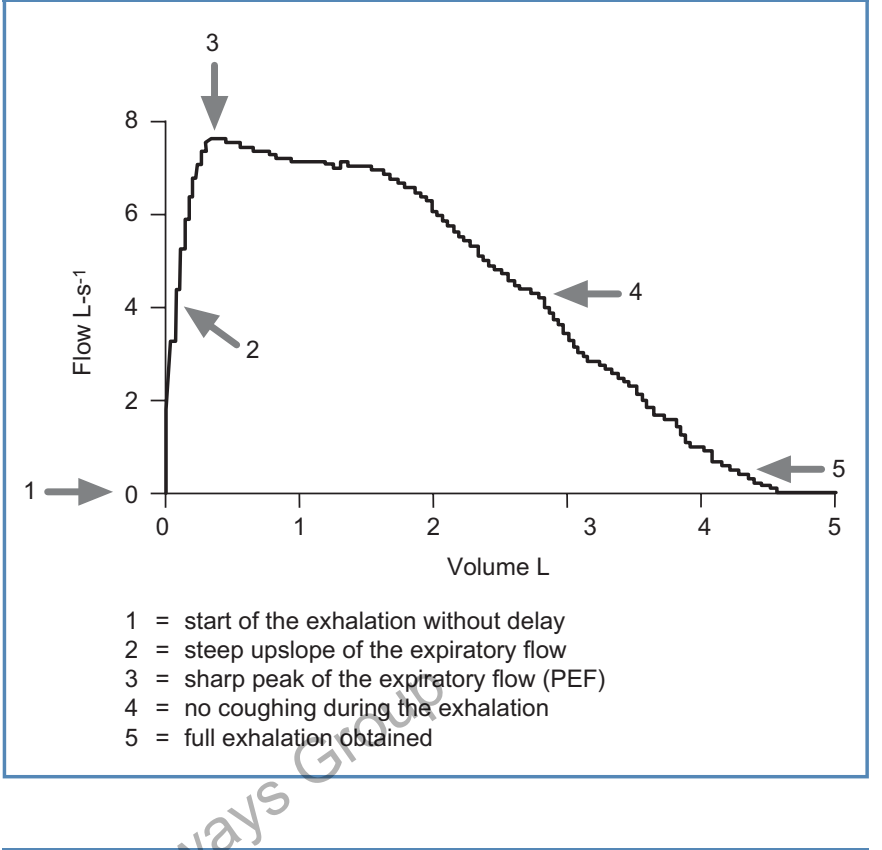

Figure 2. Origin of the study flow-volume curves.

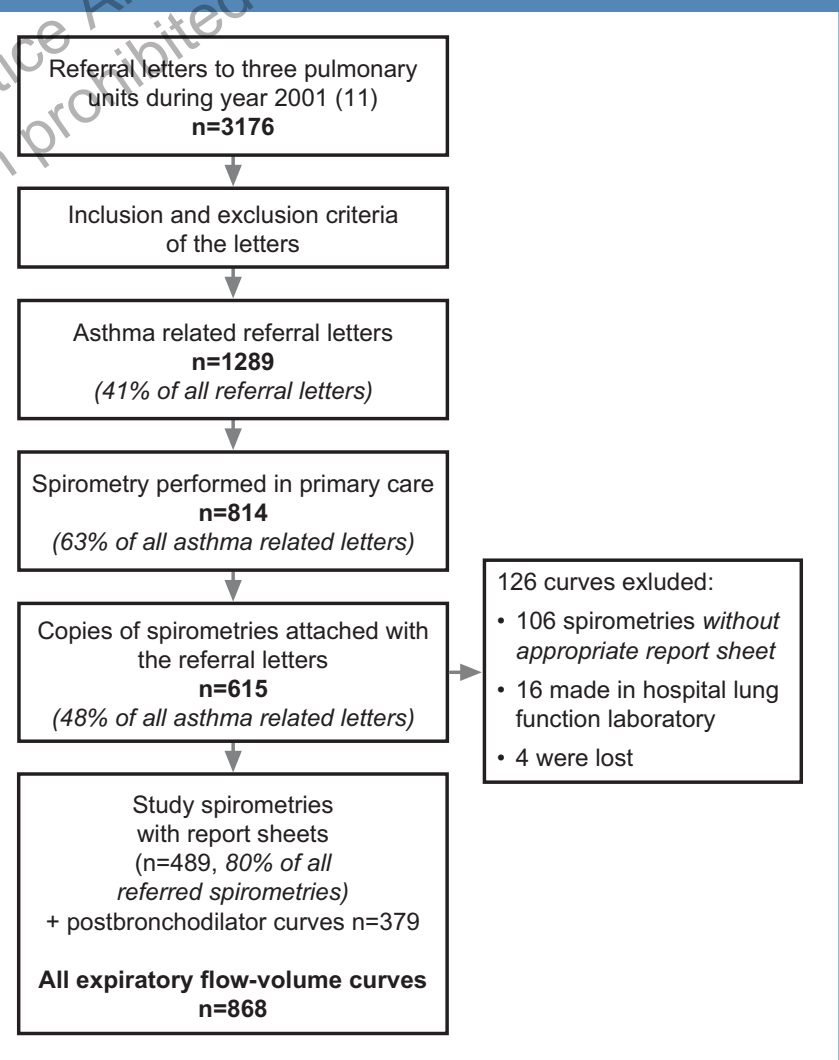

post-bronchodilation curves from the same measurement session. The criteria were found to be mainly undisputable. Disagreement occurred most often in evaluating the sharpness of the peak expiratory flow (PEF) value 


\begin{tabular}{|c|c|}
\hline Clinical information on the spirometry report sheets & $\mathrm{n}=489$ \\
\hline 1. Date when the spirometry was performed included & $99 \%$ \\
\hline 2. Indication for spirometry mentioned & $15 \%$ \\
\hline $\begin{array}{l}\text { 3. The location (ie the health care center or private practice) } \\
\text { where the spirometry was performed included }\end{array}$ & $37 \%$ \\
\hline 4. Name/ ID of the spirometry technician included & $97 \%$ \\
\hline 5. Height of the patient included & $99 \%$ \\
\hline 6. Smoking history of the patient mentioned & $87 \%$ \\
\hline 7. Duration of smoking (in years) mentioned & $74 \%$ \\
\hline 8. Patients' respiratory medication mentioned & $26 \%$ \\
\hline $\begin{array}{l}\text { 9. Time of last dose of that respiratory medication taken } \\
\text { mentioned }\end{array}$ & $30 \%$ \\
\hline 10. Patient cooperation commented & $32 \%$ \\
\hline 11. Reference values included & $100 \%$ \\
\hline 12. Source of the reference values referred (16) & $96 \%$ \\
\hline
\end{tabular}

(disagreement in 10 out of 36 curves) and whether or not exhalation of the entire vital capacity volume had occurred (disagreement in 8 out of 36 curves). Disagreement was observed especially between the physiologists and the pulmonary physicians, the pulmonary physicians being more critical in their assessments.

The final audit contained 489 spirometry reports) (80\% of all referred spirometries). Figure 2 shows the origin of these spirometry reports. In our previous study, ${ }^{14}$ all non-emergency referral letters ( $n=3176)$ to three Finnish pulmonary outpatient units sent during 2001 were scrutinised. The referrals originated from health care centres and private practices. We selected asthma-related referrals with 'asthma', 'asthma suspicion', 'asthma-related respiratory symptom', or 'obstructive lung function test result' being the original reason for the referral. On this basis $41 \%(n=1289)$ of all pulmonary referral letters from the study year were included. At least one spirometry measurement was attached with 615 (48\%) of the referral letters. All attached spirometry readings were photocopied and coded. Only flow-volume spirometry curves which were printed as final reports, and which showed specific spaces to be filled in, with clinical information concerning the patient and the measurement circumstances, were included in the study. As the inspiratory manoeuvre was seldom performed, inspiratory flowvolume curves were not analysed, even if they were available. If several spirometry readings were provided with the same referral, we selected the latest one, or the one showing a bronchodilation reversibility test. The reversibility test was
Table 2. Fulfilment of the five quality criteria in spirometries $\mathbf{7 8 \%}$ included also postbronchodilator curve).

$\begin{array}{lcc}\begin{array}{l}\text { Fulfilment of the } \\ \text { five quality criteria }\end{array} & \begin{array}{c}\text { Prebronchodilator } \\ \text { curve }(n=489)\end{array} & \begin{array}{c}\text { Postbronchodilator } \\ \text { curve }(n=379)\end{array}\end{array}$

1. Start without delay $98 \% \quad 99 \%$

2. Steep upslope $\quad 95 \% \quad 94 \%$

3. Sharp PEF $90 \% \quad 91 \%$

4. No coughing $98 \% \quad 99 \%$

5. Full exhalation $\quad 90 \% \quad 91 \%$

All criteria fulfilled

\begin{tabular}{ll} 
= good quality* & $78 \%$ \\
\hline
\end{tabular}

* The quality of all flow volume spirometries $(n=868)$ was found good in $79 \%$ of the curves.

included in 379 (78\%) study readings. In these cases, both the pre- and post-bronchodilation curves were separately assessed. Therefore, a total of 868 spirometry curves from 489 spirometry reports were included in the quality assessment (see Figure 2).

The quality of the curves according to the five predefined criteria was assessed by two clinical physiologists, JL and VJ (with 30 years and 20 years of experience in analysing pulmonary function tests, respectively). They analysed 240 and 249 spirometry reports, respectively. In order to measure the intra-rater repeatability and the inter-rater reliability, both clinical physiologists blindly recoded 25 of the curves they had originally reviewed, and 25 of the curves originally reviewed by the other. Clinical information on the patient and the test session (see Table 1) shown on the spirometry report sheets $(n=489)$ was separately collected by a trained nurse. Reference values used in the adult Finnish population were published in 1982. ${ }^{16}$ The categories for the quality criteria and clinical information were coded, and the sums of the codes for different criteria were calculated. The sums indicate the overall assessment of flow-volume curve quality and the amount of clinical information included on the flow-volume sheets. The intra-rater repeatability and inter-rater reliability of the clinical physiologists were assessed by raw agreement.

\section{Results}

We assessed the spirometry reports on 489 patients referred from primary care for pulmonary specialist consultation. Sixtytwo percent of the patients were female, with a mean age (range) of 48 (15-86). The main indications for referral were: asthma suspicion (51\%); asthma-related symptoms (25\%); and previously-diagnosed asthma (6\%). Bronchodilator reversibility tests were made in 379 cases. Significant bronchodilation response (12\% or more) of forced expiratory volume in 1 second $\left(\mathrm{FEV}_{1}\right)$ was observed in $20 \%$ of cases. 


\begin{tabular}{|c|c|c|c|}
\hline $\begin{array}{l}\text { Prebronchodilatation } \\
\text { curves } n=50\end{array}$ & Yes & No & Agreement \\
\hline 1. Start without delay & 47 & 3 & $94 \%$ \\
\hline 2. Steep upslope & 48 & 2 & $96 \%$ \\
\hline 3. Sharp PEF & 46 & 4 & $92 \%$ \\
\hline 4. No coughing & 46 & 4 & $92 \%$ \\
\hline 5. Full exhalation & 44 & 6 & $88 \%$ \\
\hline \multicolumn{4}{|l|}{$\begin{array}{l}\text { Postbronchodilatation } \\
\text { curves } n=35\end{array}$} \\
\hline 1. Start without delay & 35 & 0 & $100 \%$ \\
\hline 2. Steep upslope & 32 & 3 & $91 \%$ \\
\hline 3. Sharp PEF & 32 & 3 & $91 \%$ \\
\hline 4. No coughing & 35 & 0 & $100 \%$ \\
\hline 5. Full exhalation & 29 & 6 & $83 \%$ \\
\hline
\end{tabular}

The fulfilment of the quality criteria of the pre- and postbronchodilation curves is shown in Table 2. Each of the five criteria was fulfilled in at least $90 \%$ of curves. Sharp PEF and full exhalation were not achieved in $10 \%$ of the pre-bronchodilator curves (Figure 3). The quality of the curves was graded good (= all five criteria fulfilled) in $79 \%$ of all curves ( $n=868$ ).

Intra-rater repeatability was assessed for both of the clinical physiologists by recoding 25 curves each. The agreement was $98 \%$ and $99 \%$ respectively. Fifty curves (of which 35 also included post-bronchodilator curves) were coded by both clinical physiologists to measure the inter-rater reliability between the rates. This agreement ranged from $83 \%$ to $100 \%$. Interpretation of the full exhalation caused the most disagreement between the two reviewers (Table 3).

Clinical information provided on the report sheets is shown in Table 1. The date of spirometry testing, identification of the technician, reference values and height of the patient, were found on almost all sheets, and smoking history on more than two-thirds. The location of spirometry testing (ie. name of the health care centre or private practice where the spirometry was performed) was mentioned on $37 \%$ of the sheets, and the indication for the spirometry measurement in 15\% of cases. Use of respiratory medication and patient co-operation were commented on in a third of the sheets. If comments on patient co-operation, details of the use of respiratory medication, and data on the site where the spirometry took place were not counted, all other items were found on $84 \%$ of sheets.
Figure 3. Example of a flow-volume curve where sharp PEF and full exhalation were not achieved.

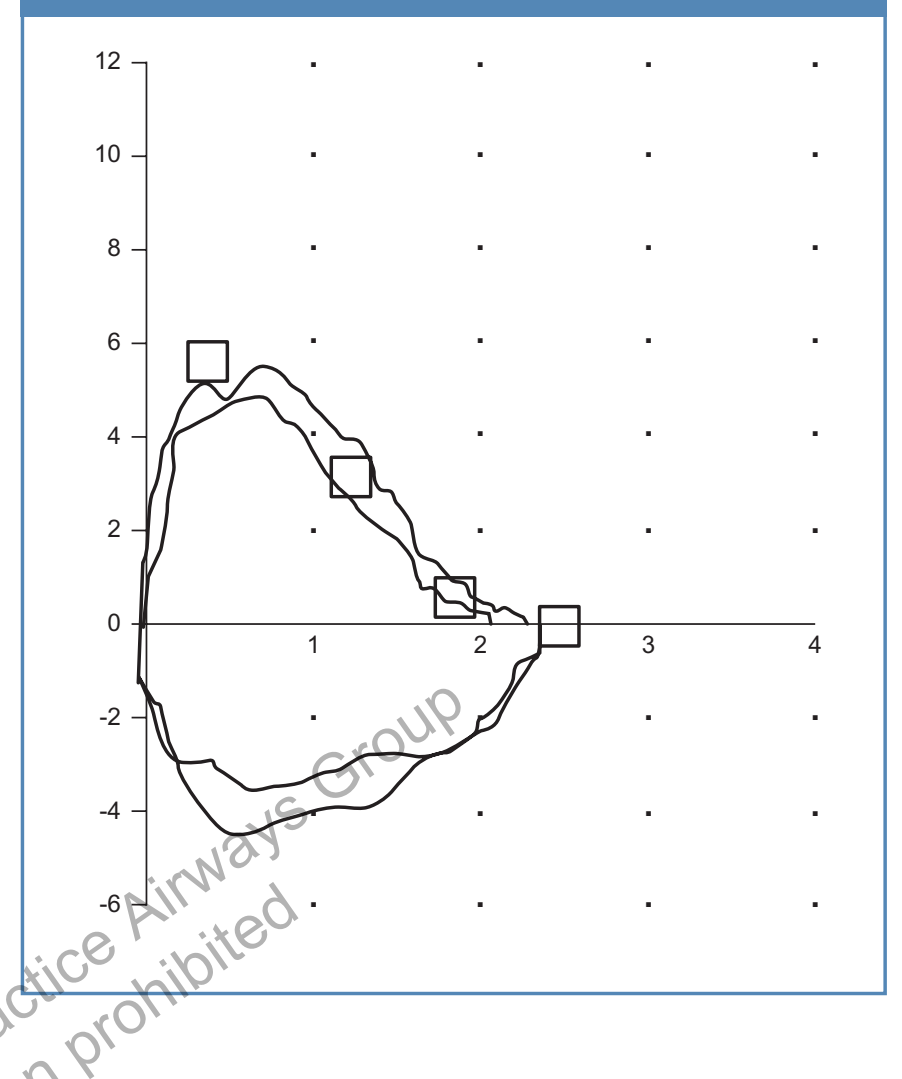

\section{Discussion}

The quality of the flow-volume spirometry curves assessed using predefined criteria was good in $79 \%$ of the curves. Sharpness of the PEF value and full vital capacity exhalation seemed to be the critical points of the spirometry test. Obtaining full exhalation has been shown to be a common quality problem. ${ }^{4,6,17}$ Clinical information such as the date of the test, patient height, and reference values were mentioned on almost all sheets. Details of the use of respiratory medication, patient co-operation, and the location of spirometry testing, were often missing.

Inter-rater agreement for quality criteria fulfillment between the two clinical physiologists was good. Assessment of the full exhalation criteria, especially regarding the postbronchodilator curves, caused disagreement most often, which was also shown in our pilot study. On the spirometry sheets, the pre- and post-bronchodilation curves were partly overlaid, and repeated copying of the spirometry sheets may have decreased the visual quality of the curves (Figure 3). Interpretation of the full exhalation volume from these curves may be inconsistent if the forced vital capacity (FVC) obtained in the post-bronchodilation phase is smaller than the prebronchodilation FVC, even though both the curves may look appropriate. Usually, only the expiratory flow-volume curves were performed and reported. It would have been easier to 
assess whether the full exhalation criteria were met consistently if the maximal inspiratory curves were also measured and reported.

The value of the clinical information given on the spirometry report sheets is seldom discussed. However, the need for that information is obvious from a clinical perspective. For example, comparison of the various curves can be difficult later on if information on the location and date of spirometry testing are missing. In order to get a reliable exhalation manoeuvre and test result, good patient co-operation is essential. Yet this information was mentioned on only one-third of the spirometry report sheets. Similarly, previous use of respiratory medication was found on only one-third of report sheets, although all the study spirometry flow-volume sheets had specific space available for comments on both patient co-operation and respiratory medication. In a recent study, trained GPs were shown to use spirometry to evaluate the response to recently-initiated treatment with inhaled steroids. ${ }^{18}$ Interpretation of the test results and comparison with previous spirometries are not reliable without data on patient co-operation and recent use of both short-acting and long-term respiratory medication.

Walker et al have shown that the use of spirometry in primary care increases the rates of diagnosis of COPD and asthma, and leads to improvements at least in COPD treatment. ${ }^{19}$ Use of bronchodilator reversibility testing in this setting may be important to avoid misdiagnosis and ondertreatment. The present study has shown that bronchodilat or reversibility testing was commonly combined with spirometry measurement in our primary care practices. In the majority (78\%) of the study spirometry sheets, post-bronchodilator curves were provided.

This study was specifically designed to evaluate the quality of primary care spirometry by visual assessment of the spirometry curves, and to study the quantity of clinical information provided with the spirometry report sheets. Evaluation of the actual value of performing spirometry in terms of clinical diagnosis was not in the scope of the study. Therefore, we did not try to analyse whether these spirometry measurements were useful in aiding the achievement of the correct diagnosis.

There were limitations in the study protocol. Since we assessed only spirometry reports enclosed with the referral letters from primary care to specialists, we do not know how well they represented all spirometry measurements in primary care. Reproducibility of the exhalation is an important additional quality criterion. This could not be evaluated by our retrospective analysis of the curves. We were not able to evaluate the adequacy of device calibration, either. Assessing the amount of clinical information gained from the spirometry sheets was one focus of this study. Therefore, only those flow- volume report sheets with space left for this information were included. This might have improved the results, because adding information on the medication or patient cooperation is more likely to happen if there is available space. However, we know that this kind of spirometry report sheet is commonly used in our primary care setting.

In the future, smaller, cheaper and simpler office spirometers may replace the standard flow-volume spirometry machines in primary care settings. These various new machines, which often give only numerical values, may be practical in the screening of obstructive pulmonary disease. However, especially for diagnosis, it is essential to use high quality spirometers which display flow-volume curves; the ability to see displayed flow-volume curves is an important part of both the quality control and interpretation of spirometry testing. The curves should also be saved digitally in an electronic patient record system for later comparison during patient follow-up visits.

The quality of the spirometry curves enclosed with the asthma-related referral letters was good. Primary care spirometry measurements, especially with a reversibility test, offer additionlal high quality information when the patient is referred for a specialist consultation; the previous spirometry measurements can be compared with values obtained during the initial specialist consultation to aid the diagnostic process, and may even obviate the need for further spirometries. Continuous education and quality assurance should draw attention to the importance of providing adequate clinical information in order to improve further the usefulness of primary care spirometry to both GPs and specialists.

\section{Main discussion points}

The quality of the primary care flow-volume spirometries assessed using predefined criteria was good in $79 \%$ of the curves. Sharpness of the PEF and successful exhalation of the entire volume seemed to be the critical points of the spirometry test. The ability to see displayed flow-volume curves is an important part of the quality control of spirometry testing. Value of the clinical information on the report sheet should also be emphasized. Interpretation of the test results and comparison to previous spirometries are not reliable without data on patient co-operation and recent use of both the short-acting and long-term respiratory medication.

\section{Conflicts of interest}

None declared

\section{Acknowledgements}

The Väinö and Laina Kivi Foundation, The Tampere Tuberculosis Foundation and Filha supported this study.

\section{References}

1. National Institutes of Health. Global initiative for asthma. Global strategy for asthma management and prevention. Updated 2006. NIH Publication. 
http://www.ginasthma.com/

2. Rabe KF, Hurd S, Anzueto A, et al. Global strategy for the diagnosis, management, and prevention of chronic obstructive pulmonary disease: GOLD Executive Summary. Am J Respir Crit Care Med 2007;176:532-55. http://www.goldcopd.com/

3. Chavannes N, Schermer T, Akkermans R, et al. Impact of spirometry on GPs' diagnostic differentation and decision-making Resp Med 2004;98:1124-30

4. Eaton T, Withy S, Garrett JE, Mercer J, Whitlock RML, Rea HH. Spirometry in Primary Care Practice. The importance of quality assurance and the impact of spirometry workshops. Chest 1999:116:416-23.

5. Schermer TR, Jacobs JE, Chavannes NH, et al. Validity of spirometric testing in a general practice population of patients with chronic obstructive pulmonary disease (COPD). Thorax 2003;58:861-6.

6. White P, Wong W, Fleming T, Gray B. Primary care spirometry: test quality and the feasibility and usefulness of specialist reporting. Br J Gen Pract 2007;57:701-05.

7. Pellegrino R, Viegi $G$, Brusasco $V$, et al. Interpretative strategies for lung function tests Eur Respir J 2005;26:948-68.

8. Asthma programme in Finland 1994-2004, with introduction by Haahtela T, Laitinen LA. Report of a Working Group. Clin Exp Allergy 1996;26:1-24.

9. Haahtela T, Tuomisto LE, Pietinalho A, et al. A Ten-year Asthma Programme in Finland: Major change for the better. Thorax 2006; 61:663-70

10. Sovijärvi ARA, Piirila P, Korhonen O, Louhiluoto E, Pekkanen L, Forstedt M. Performance and evaluation of spirometric and PEF measurements, offprint 3. KP-paino, Kokkola: Kliinisten laboratoriotutkimusten Laaduntarkkailu Oy; Moodi 1995 (in Finnish).
11. Erhola M, Makinen R, Koskela K, Bergman V, Klaukka T, Makela M et al. The Asthma Programme of Finland: an evaluation survey in primary health care. Int J Tuberc Lung Dis 2003;7:592-8.

12. Tuomisto LE, Kaila M, Erhola M. Asthma programme in Finland: Comparison of adult asthma referral letters in 1994 and 2001. Respir Med 2007;101:595-600.

13. Tuomisto L, Erhola M, Kaila M, et al. Asthma Programme in Finland: High consensus between general practitioners and pulmonologists on the contents of an asthma referral letter. Prim Care Respir J 2004;13:205-10. doi:10.1016/j.pcrj.2004.04.001

14. Tuomisto L, Erhola M, Kaila M, et al. The Finnish National Asthma Programme: Communication in asthma care - quality assessment of asthma referral letters. J Eval Clin Pract 2007;13:50-4.

15. American Thoracic Society. Standardization of spirometry: 1994 update. Am J Respir Crit Care Med 1995; 152:1107-36.

16. Viljanen AA, Halttunen PK, Kreus KE, Viljanen BC. Spirometric studies in nonsmoking health adults. Scand I Clin Lab Invest 1982;159:5-20.

17. Akhtar R, Wilson A. A comparison of spirometry in general practice and a pulmonary function laboratory. Prim Care Resp J 2005;14:215-20. doi:10.1016/j.pcrj.2004.12.005.

18. Poels PJP, Schermer TRJ, Jacobs A, Akkermans RP, Bottema BAM, van Weel C. Variation in spirometry utilization between trained general practitioners in practices equipped with a spirometer. Scand J Prim Health Care 2006;24:81-7.

19. Walker PP, Mitchell P, Diamantea F, Warburton CJ, Davies L. Effect of primary care spirometry on the diagnosis and management of COPD. Eur Respir $J$ 2006;28:945-52. 5

\section{Available online at http://www.thepoji.org}

